\title{
Assessment of the Appropriateness and Adequacy of the Existing Physical Infrastructure in Mitigating Aviation Risks at Wilson Airport, Kenya.
}

\author{
Paul Muthee Kanyi ${ }^{1}$,Dr.P.K Kamau ${ }^{2}$, Prof, C. Mireri ${ }^{3}$ \\ ${ }^{1,2,3}$ Department of Environmental Planning and Management. School of Environmental Studies, Kenyatta, \\ Nairobi, Kenya Correspondence
}

\begin{abstract}
The aviation sector is one of the most important sectors for any country especially its ability to promote interconnectedness within countries as well as between countries. However, the sector faces many risks caused by various emergencies and accidents associated with the sector, and much so in the precincts of airports. The impact of these accidents causes monumental social, economic and environmental consequences to victims. The exponential growth of the sector in the country calls for special attention by relevant stakeholders to devise strategies to address disaster preparedness issues. This is especially due to the fact that the country has already experienced a number of aviation disasters and mishaps related to the industry. Consequently, this study sought to assess the appropriateness and adequacy of the existing physical infrastructure in mitigating aviation risks in the airport. This study was carried out at Wilson airport located in Nairobi West. The qualitative design was applied in this study to analyze and describe the effects of land use changes on airport and flight safety in a rapidly growing aviation sector. The target population for the study comprised of 50 aviation regulators, 50 air operators, 100 service providers and communities living around the Airport. Primary data was collected by use of questionnaires, interview guide and Focused Group Discussions while Secondary data were collected from written or published records and maps from the Kenya National Bureau of statistics. Quantitative data was analysed by use of descriptive statistics such as frequencies and percentages while qualitative data was analysed using content analysis. The study found that $62 \%$ of the respondents indicated that Wilson Airport does not have the capacity in terms of space and facilities and that $75 \%$ of the respondents indicated Air field capacity was inadequate. The study also found that $63.2 \%$ of the respondents indicated thatAirport Visual Aids (such as pavement markings) were inadequate, $57.9 \%$ of the respondents indicated Airport Lighting was inadequate, $40.4 \%$ of the respondents indicated that runway orientation, length, width, and pavement strength were inadequate and $30(56 \%)$ indicated that taxi ways were inadequate. The results for correlation analysis showed that there is a positive correlation between the disaster preparedness and appropriateness and adequacy of the existing infrastructure with a Pearson's Correlation Coefficient of $r=0.769$ and a level of significance of 0.000 meaning that is it statistically significant.
\end{abstract}

Keywords:Aviation risks, physical infrastructure, preparedness

\section{INTRODUCTION}

An airport incident can occur anywhere, at any time - day or night, under any weather condition, and varying degrees of magnitude; it can occur instantly or develop slowly; it can last only a few minutes or go on for days (United States Department of Transport, 2009). It can be natural, such as a hurricane or earthquake, or it can be 'man-made', such as a hazardous materials spill, civil unrest, terrorism, and major fire or power outage. Moreover, emergencies of the same type can differ widely in severity, depending on degree of warning, duration, and scope of impact (United States Department of Transport, 2009).

An airport incident can occur anywhere, at any time - day or night, under any weather condition, and varying degrees of magnitude; it can occur instantly or develop slowly; it can last only a few minutes or go on for days (United States Department of Transport, 2009). It can be natural, such as a hurricane or earthquake, or it can be 'man-made', such as a hazardous materials spill, civil unrest, terrorism, and major fire or power outage. Moreover, emergencies of the same type can differ widely in severity, depending on degree of warning, duration, and scope of impact (United States Department of Transport, 2009).

According to Gooch (2007), airport aviation increases the economy of a nation by providing employment globally. For instance in Canada, the airport industry generates $\$ 8$ billion dollars and provides 150,000 job opportunities annually. The International Civil Aviation Organization (2006) noted that 2.1 billion passengers travelled by flight globally. This has great influence on global markets. Airport aviation improves global socio-economic development. However, there is growing concern over increasing aviation-related 
disasters globally. Most of these disasters occur when aviation and related businesses around airports are increasing thus posing enormous risk and dangers to the immediate precincts as well as to adjoining airports. Though aviation disasters occur worldwide, there is special concern for aviation disasters in Africa (Kwiatkowski, 2001). The potential for disaster exists everywhere, and there is resultant devastating cost: suffering and loss of life and. Emergencies are perceived as low probability events and preparedness requires time and finances. This often results in planning needs being overlooked. Lack of planning can cost airports and communities a high price including: health and safety problems, social disruption, lawsuits, negative publicity, liability, post-emergency psychological effects. While every contingency cannot be anticipated and prepared for, a strong emergency preparedness programme can limit negative these impacts.

Dannat (2002), observes that air transport has remained one of the most regulated and restrictive industries in international trade. Domestic deregulation and liberalization progress at an uneven pace and liberalization of the international markets has yet to overcome numerous obstacles. Air carriers therefore need to build extensive global networks to realize economies, scope and density and meet consumer demands. The need for expansion and the increase in consumer demand therefore brings the global aviation industry into perspective.

In the last two decades, Kenya has witnessed a number of fatal aviation disasters including the Busia (24th January 2003), Marsabit (10th April 2006), Narok (14th June 2008) and Ngong plane (10th June 2012) disasters in which prominent Kenyan political, administration and civil servant leaders have lost their lives (Mutugi and Maingi, 2011: 40). Reports on inquiries into these disasters have pointed to poor aviation environments and non-compliance with international aviation standards and regulations (Mokaya and Nyaga, 2009). Separately, a report by the Aviation Safety Networks (ASN, 2010), provides data of several aviation accidents that have occurred in Kenya between the years 2006 and 2009. The report further observes that it is evident that $50 \%$ of the air accidents occurred during take-offs, $28.6 \%$ during landing and $21.4 \%$ during cruise. Take-offs and landings accounted for $78.6 \%$ of the accidents. This is despite the fact that Kenya is a signatory to the International Civil Aviation Convention (ICAC) that sets the standards and regulations to which airports and aerodromes must conform (Mokaya and Nyaga, 2009).

Suda (2000) states that the development of airfields and airports in Kenya requires terrain that is level and free of artificial obstructions in the vicinity. This is similar to other global scenarios. As a result of these factors, airports have tended to develop on large flat sites and affect their social environment and vice versa. Airports originally constructed far from town are becoming embedded in metropolitan areas that grow around them. People live and work much closer to the airport fence than airport and city planners anticipated.

The Kenya Association of Air Operators (KAAO) has constantly warned that airports such as Wilson Airport pose real danger to aviation security and safety due to encroachment onto airport space by residential and commercial buildings, which ultimately renders flight paths invisible to pilots and inhibits smooth take-off and landing. Wilson Airport is currently facing an acute problem of encroachment onto its flight path by exponential real estate developments. Considering it is an airport with approximately 120,000 landings and take-offs annually, as reported by the Kenya Civil Aviation Authority (KCAA, 2007), these encroachments pose a real risk on safety.

Despite the increase in threats to aviation safety challenges in Kenya, the KCCA, in response to the national developmental goals envisioned in the Kenya Vision 2030, has put in place measures to ensure Kenyan air operations meet international safety and security requirements to meet the international standards including: infrastructural facilities, communication facilities, and security checks (Hudson, 1997). To achieve this, the Authority needs to augment its capacity to deliver quality regulatory oversight services and ensure its compliance to civil aviation regulations (Kenya Vision 2030 Blueprint, 2009).

Africa's aviation disaster record, and the question marks raised especially by key stakeholders in the aviation industry such as KAA, Association of Air Operators and KCAA concerning compliance to aviation standards and regulations in Kenya, presents researchers and scholars an opportunity to examine these issues in a detailed and systematic way to help reverse the negative aviation record in Kenya and Africa (Oladele, 2005). This study examines the Kenyan aviation disaster risk preparedness context with and recommends means to mitigate disaster occurrence and enhance disaster risk preparedness. It also adds value to aviation studies in the country.

\subsection{History of Wilson Airport}

The history of Wilson Airport (WAP) dates back to the First World War. Commercial routes were pioneered by Imperial Airways and its successor British Overseas Airways Corporation (BOAC) in the 1920's. In July 1929, Wilson Airways Ltd was formed by Mrs. Florrie Wilson to operate from an airfield in Dagoretti Corner, Nairobi. Later, the airport was relocated to the present site of Wilson Airpor and originally called Nairobi Aerodrome. The construction work was carried out by the Public Works Department. By 1933 two 
murram (non-tarmac) runways had been laid. The Imperial Airways then commenced operation of an airmail service to Kisumu in July that the same year (http://www.kaa.go.ke/airports/wilson).

In 1962, the GoK renamed the aerodrome 'Wilson Airport' to honour its founder. Today the airport has expanded to become a major domestic airport, a gazetted border control point accommodating short-haul scheduled domestic flights and services, international, and private and charter flights. Wilson Airport is situated at latitude 0118 's and longitude 36 48'49'E, 5km from the Nairobi city centre, and borders Nairobi National Park to the immediate south. It is ICAO Class 2, Category 5, and holds the code HKNW. Currently, Wilson Airport is one of the busiest airports in terms of aircraft movement in East and Central Africa. Domestic flights constitute $90 \%$ of the total flights from the airport with international flights accounting for $10 \%$. The airport is a fast and convenient gateway from Nairobi into Kenya's magical interior. Destinations served from the airport include Maasai Mara, Mombasa, Amboseli, Lamu, Diani, Lokichogio, Nanyuki and Kilimanjaro. It is also a modern hub of general aviation in East and Central Africa (https://www.kaa.go.ke/airports/wilson).

\subsection{Problem statement}

Wilson Airport Nairobi is the smallest of the two civil aviation facilities in the city. The airport, which is used mostly by general aviation traffic, caters for both international and domestic traffic. The facility is mainly used by tourism, agriculture and health sectors of the economy. Wilson Airport handles about 120,000 landings and take-offs every year, most of it local and regional traffic. As a result of faster check-in times and fewer flight delays, as compared to Nairobi International Airport, Wilson Airport is commonly used by business executive aircraft for both domestic and International travel. Common domestic destinations from Wilson Airport include Kisumu Airport, Mombasa International Airport and Eldoret International Airport.

Despite existence of comprehensive policies on aviation safety in Kenya, critical aviation safety challenges continue to emerge in the existing airports. Over the past decade, Wilson airport has faced different challenges ranging from constrained spaces and aviation related accidents. The airport is constrained by expansion and development space largely due to expansion of aviation businesses as well as developments in its adjoining neighbouring areas. Among the many security and safety concerns raised have been encroachment into airport space with claims that illegal structures and numerous other high-risk business developments within and around the airport have significantly affected flight safety in the airport. All these increasing infrastructural developments pose a threat to aviation activities at the airport.

Different studies have been done in airports in Kenya. Mukaria (2013) did a study on knowledge, awareness and conformity to International Airport emergency preparedness standards: the case of Wilson Airport in Nairobi, Kenya. The study found that dissemination of information among stakeholders was average resulting into low cooperation in the cases of emergency at the Wilson Airport. Obwaya (2010) did a study on disaster risk reduction strategies in preparedness at Jomo Kenyatta International Airport (JKIA) Nairobi Kenya. He found that JKIA plans, facilities and personnel cannot handle a large-scale disaster. No study has been done on the effects on land use changes on airport safety in Kenya. This study therefore assessedthe appropriateness and adequacy of the existing physical infrastructure in mitigating aviation risks in the airport.

\section{LITERATURE REVIEW}

This section presents theoretical and empirical review

\subsection{Chaos Theory}

One counter to the linearity of the lifecycle approach was to explore whether ChaosTheory which emphasizes multi-directional causality and lack of predictability hasutility for understanding crisis management. Chaos theory is built on the two ideas hatsystems, no matter how complex, rely on an underlying order, and that within suchsystems very small changes or events can cause very complex behaviors or outcomes.

Recognition of this non-linear interaction between components prompted PriscillaMurphy (1996) and later Matthew Seeger (2002) to advance the application of chaostheory to crisis management. Chaos theory suggests that it is impossible to detect simple linear cause and effect relationships. Instead, there are many variables that interact in convoluted ways to produce disaster. Chaos theory would thus recommend that vulnerability be reduced by addressing multiple variables simultaneously.

The theory of chaos stresses that the world does not necessarily work as a linear relationship with perfectly defined or with direct relations in terms of expected proportions between causes and effects. The chaos occurs when a system is very sensitive to the initial conditions. These initial conditions are the measured values for a given initial time. The presence of chaotic systems in nature seems to place a limit on our ability to apply physical deterministic laws to predict movements with any degree of certainty. Indeed, one of the most interesting subjects in the study of chaotic systems is the question of whether the presence of chaos may or may not produce ordered structures and patterns on a wider scale. In the past, the dynamic systems showed up 
completely unpredictable and the only ones who could aspire to be understood were those that were represented by linear relationships, which are not the rule. On the contrary, there are some situations clearly isolated.

Chaos theory was used to explain how response to disasters may compromise its management. Focusing on how the airport is prepared to prevent and handle disaster cases, the theory helped in explaining how any disasters and disconnect in handling disasters would compromise disaster management.

\subsection{Appropriateness and adequacy of the existing physical infrastructure}

According to Antonio (2003), some airports are at saturation point leading to flight delays, especially during bad weather, and when there is industrial action. However, European airspace is more congested than Europe's airports. If efforts to provide airspace capacity are unsuccessful, the capacity problem at airports is likely to worsen. As traffic continues to increase, the inability of air transport systems to cope with demand is increasing. Over time, the public discourse has focused on lack of airspace capacity in Europe. But airspace has different meanings for the different players involved. The whole chain of events that make up the air transport system, including the need to ensure safety and to protect the environment, determines capacity. This study therefore sought to find out the capacity of Wilson Airport in relation to the number of airplanes it handles.

Airport capacity is constrained by air traffic movements or terminal passenger numbers. At different times of the day capacity constraints will vary in any airport. Congested airports are generally coordinated and the function of the coordinators is to limit the number of available slots to balance the most restrictive constraint. This kind of coordination is only applicable in scheduled airports. Some charter airports are not coordinated but might be very congested, the best example being Heraklion airport in Greece. There is lack of standardization in coordination at airports. One airport may accept an average delay of three minutes while another may accept five minutes for setting the number of available airport slots. Capacity in the air in the immediate vicinity of an airport, and the ability of the airport air traffic control system and its runway approach facilities to manage traffic to and from the runways, may also have a bearing on general airport capacity. Capacity on the ground must match capacity in the air, and vice versa: only a coherent approach addressing all the elements regarding capacity will result in overall improvement in airport capacity (ECAC/EUROCONTROL, 2001). This study sought to find out whether there are changes to land use around Wilson Airport and how the land use changes affects its land size.

Capacity analysis is a complex process as capacity is determined by the number and placement of runways and taxiways, the types of navigation aid, and air traffic control equipment and facilities. But other variables such as aircraft performance, the mix of aircraft types, pilot proficiency, weather, and runway closure also affect how much airport capacity can be used at a given time. The capacity in uses is often less than the capacity that would be available if there were no limitations. According to Air Traffic Management (ATM) $2000+$ Strategy, capacity is a complex mix of access to airports, airspace and services, predictability of schedules, flexibility of operations, flight efficiency, delay, as well as network effects. Clearly African airports need to increase airport capacity to meet the needs of the liberalized internal and global air transport markets(Antonio, 2003).

\subsection{Airport safety management}

The aviation industry has always quoted safety at the forefront of its priorities. As a general rule it has demonstrated diligence in learning from its mistakes and implementing changes that lead to further improvement. This somewhat reactive approach produced a steady decline in accident rates until the mid-1980s. Since then, the fatal accident rate in air transport operations has remained fairly stable, despite a growth in traffic during the same period. This trend implies little improvement in safety on the operation/accident ratio, and suggests that as traffic grows, the total number of accidents will grow accordingly (Ayres, 2009).

The ICAO, recognizing these facts and that "the public's perception of aviation safety is largely based on the number of aircraft accidents rather than the accident rate", issued a resolution to "reduce the numbers of accidents and fatalities irrespective of the volumes of air traffic". The ICAO further provides guidance on how to achieve this resolution, including the recommendation to "develop a civil aviation safety management framework and recommendations for improving safety" (ICAO, 2004).

In recent years a great deal of effort has been devoted to understanding how accidents happen. It is generally accepted that most accidents result from human error. It would be easy to conclude that these human errors indicate carelessness or lack of skills on the job, but such a statement is not accurate. Accident investigators are finding that human error is only the last link in a chain that leads to an accident. Accidents cannot be prevented by changing people; they can be prevented only when we address the underlying causal factors (Ayres, 2009).

There are two ways of thinking about safety. The traditional way is that safety has been about avoiding costs. In this sense, many aviation organizations have been bankrupted by the cost of a single major accident. 
This makes a strong case for safety, but the cost of occurrences is only part of the story. Efficiency is the second way of thinking about safety. According to Ayres (2009) safety and efficiency are positively linked. Safety pays off in reduced losses, enhanced productivity and lower insurance costs.

\subsection{Disaster Risks and Preparedness in the Aviation sector}

Once a disaster has occurred, a set of activities has to be put in motion, aimed at firstly satisfying the immediate needs of the victims, their rehabilitation and the reconstruction of any infrastructure that may have been damaged or destroyed. According to Kapoor (2009), the recovery measures, both short and long term, will include returning vital life-support systems to minimum operating standards; public information and health and safety education; economic impact studies; and counseling programmes. This requires certain procedures, as haphazard response can be sometimes problematic. Policies and objectives should actually guide the recovery, which should have been put in place for some time, tested and proved beyond doubt (FEMA, 2006).

Coordination is an essential ingredient in a disaster preparedness plan. This means arrangements and preparations put in place not only to prevent a disaster, but also to be implemented once a disaster occurs. Such plans must be both horizontal and vertical in terms of duty allocation among all the people designated to be involved, should a disaster happen. The team should be on call 24 hours a day so that in case of an emergency there is no delay in the response team (Salvano, 2002).

The necessary resources that add value to the professional training should back this team. Without this preparedness, the response and recovery operation will rapidly disintegrate. For effective response to be achieved, however, a structure for decision-making and coordination of the action plan, and the actual response must be put in place. In terms of disaster relief operations, the range of relief requirements is normally very extensive. Some of the major requirements include shelter, food, medicine, a communication system, logistics system, social workers and counsellors and a multiplicity of others (UN/ISDR, 2008).

Throughout all the activities that are meant to promote disaster preparedness, the ultimate objective should be to have plans in place that are not only agreed upon by stakeholders, but also implementable given the available resources both material and manpower. Over-ambitious plans, especially with inadequate resources, are bound to fail and lower the credibility of the organization in the eyes of the public. Indeed, any disaster preparedness plan must have adequate resources that have been committed and readily available (Salvano, 2002).

For disaster response and recovery plans to be effective and hence successful, it is important for the responders to know what to do and how to do it in case of a disaster, what is described as empowering the community to participate in disaster recovery (ISDR, 2003). For this reason, an essential part of disaster preparedness and recovery plan is the creating awareness among those who may be threatened by disaster such as an air crash at JKIA. These could include people residing near the airport.

\section{Phases of a disaster}

Disaster management is a cyclical process; the end of one phase is the beginning of another, although one phase of the cycle does not necessarily have to be completed in order for the next to take place. Often several phases are taking place concurrently. Timely decision-making during each phase results in greater preparedness, better warnings, reduced vulnerability and/or the prevention of future disasters. The complete disaster management cycle includes the shaping of public policies and plans that either addresses the causes of disasters or mitigates their effects on people, property and infrastructure (Carrilo, 2010).

\section{Mitigation and preparedness phase}

The mitigation and preparedness phases occur as improvements are made in anticipation of an event. By embracing development, a community's ability to mitigate against and prepare for a disaster is improved. As the event unfolds, disaster managers become involved in the immediate response and long-term recovery phases.

\section{Emergency Phase}

Disaster strikes. There is major disruption of the local community. Mitigating measures must immediately be taken against the disaster. Emergency response activities are those carried out during the actual emergency or immediately prior to it. This may involve emergency assistance during the disaster, and actions taken in the immediate aftermath during the time when the community is rather disorganized and basic services and infrastructure are not fully functioning. The impact phase of a disaster can vary from the slow, low-threat build-up associated with some types of floods to the violent, dangerous and destructive outcomes associated with tornadoes and explosions. The greater the scope, community destruction and personal losses associated with the disaster, the greater the psychosocial effects (Garatwa\&Bollin, 2002). 
Depending on the characteristics of the incident, people's reactions range from constricted, stunned, shock-like responses to the less common overt expressions of panic or hysteria. Most typically, people initially respond in confusion and disbelief, and focus on the survival and physical well-being of themselves and their loved ones. When families are in different geographic locations during the impact of a disaster (e.g. children at school, adults at work), survivors will experience considerable anxiety until they are reunited.

\section{Response phase}

The response or relief phase refers to the time period for humanitarian assistance, when steps are taken to save lives and to provide essential supplies to those most affected. It includes such activities as search, rescue, evacuation, provision of shelters, first aid, emergency medical care and protection, temporary restoration of transportation and communication routes, preliminary repairs to essential public utility services and early actions to register victims and record damage to public andprivate property. This stage may vary in its duration but, in general, it is relatively brief, depending on the magnitude of the disaster (Garatwa\&Bollin, 2002).

\section{Rehabilitation phase}

The rehabilitation or transition stage includes activities required to return normality to the affected areas and communities. It includes non-definitive repairs to housing and buildings, and to transport and public utility service infrastructure. Problems related to the emotional and psychological recovery of the inhabitants of the regions affected by the disaster are to be addressed here. Return to work, creation of new jobs, availability of loans and financial resources, and immediate start-up projects related to the consequences of the disaster are among recovery measures that most help the victims and affected communities. Finally, the reconstruction stage includes activities designed to rearrange the affected physical space and environment, and enable the allocation of resources in accordance with the new social priorities arising from the effects of the disaster (Garatwa\&Bollin, 2002).

\subsection{Disaster preparedness in Aviation sector in Africa}

African aviation disaster management efforts have been described as passive (Momoh and Akinyede, 2008). This is in contrast to the relatively better developed economies of Europe and America which have made remarkable strides in disaster management and reduction. In 2008, the Institute of Security Studies (ISS) Report showed that Africa suffers from major concerns and challenges in aviation security and safety (Kapchangah, 2008) than most parts of the world. The report says that African aviation is in a very bad state of affairs and that most of the concerns are associated with African aviation lack of compliance with international aviation guidelines. One the other hand the ICAO regional report indicates that safety is the urgent priority for Africa (ICAO, 2011)

In terms of addressing most African aviation problems, the continent has been blamed of having country by country efforts to address problems instead of addressing the issues collectively (Oladele, 2005). The result of this has been that there has been disunity especially in award of airworthiness certificates for aircrafts and pilots. This has meant increased risk and vulnerability to aviation disasters in the continent. Other experts have also raised similar issues concerning the air safety issues (Phillips, 2002).

Overall, mismanagement and poor infrastructure has been identified as the greatest hard cap and leading causes of airport accidents. The best way to reduce some of Africa's airports accidents is by assigning the right people in the right places while emphasizing training and professionalization of the various departments associated with management of ports to be of great importance. These studies admit and provide evidence that indeed aviation disasters in Africa are real and pose a critical challenge to the development and sustainability of the industry. It is for this purpose that this study will be assessing the preparedness of Wilson airport in case any of this prevalent disasters and risks do occur.

Although aircraft accidents are rare, maintaining compatible land uses around airports helps to reduce the risk to those on the ground near airports, as well as those persons traveling by air, should an accident occur. Studies have been conducted to assess trends in aircraft accident locations and their relationship to the ends of runways to define zones of risk.

The NTSB conduced a study that assessed aircraft accident statistics from 1978-1987. Based upon those findings, it was concluded that of the 500 accidents contained in the data set, only 246 were relevant to the study of accident locations. A subsequent study entitled The Development of an Accident Database to Structure Land Use Regulations in Airport Runway Approach Zones, Part II, 1998, was able to include 873 accidents that covered a period from 1983 to 1992 (Cooper, 1998). It has been recommended based on the findings of these two studies, that additional data is necessary when accident and incident reports are filed. For example, additional information related to the precise location of the accident, the extent and location of any related debris field, as well as the point of take-off or touchdown and information regarding the surrounding terrain and land uses are recommended to be collected. 
Additionally, an assessment of the amount of risk associated with land use incompatibility also is necessary. For example, in some discussions, people who support compatible land use planning argue that while the probability of an aircraft accident happening in any one location is relatively small, it only takes one accident for it to have potentially catastrophic consequences.

Others who are not as favorable to this planning effort argue that the risk of an accident is so minute that there is little reason to plan for it. Consequently, local communities need to assess the general level of risk that they are comfortable assuming with regards to the potential of an aircraft accident and the subsequent impacts to the local community and property owners who may be in proximity to the accident site.

European countries, particularly in the United Kingdom and the Netherlands, have increasingly been performing risk analyses in developing land use compatibility guidance. The results of these European studies, along with a study conducted in the United States by the Minneapolis-St. Paul International Airport Joint Airport Zoning Board, suggest current airport land use compatibility criteria may overstate the risk to people and property on the ground. Models developed by the United Kingdom National Air Traffic Services Limited illustrate areas of risk result in a triangular contour with the base adjacent to the end runway and tapering to a point away from the runway.

As a result of these findings from the European community, it would be desirable to have the development of a risk model to determine land use compatibility criteria that could be applied at different airports within the United States, based upon the additional aircraft accident data that is now available. An additional 17 years of data has been collected since the 1992 Cooper Study (Cooper 1998). This model would be available for use by state and local planners and elected officials, as well as airports and consultants, to analyze risk at an airport. Availability of this model would help to establish a more rational and customized approach in defining criteria for airport land use compatibility and acceptable levels of risk.

It should be noted that additional guidance would be necessary to accompany this sort of model to provide local policy decision makers to determine acceptable levels of risk compared to the tradeoff for development opportunities in order to reduce risk of aircraft accidents. The willingness will vary from community to community and would need to be based upon local assessment of the potential risks versus the anticipated cost, should an accident occur.

\subsection{Aviation Disasters in Kenya}

Kenya has not implemented a safety management system in her aviation industry (Mokaya and Nyaga, 2009). As of 2006, the country has been classified as non-compliant with International Civil Organization (ICAO) regulations. Aviation association have actually criticized the lethargy exhibited by the Kenya Aviation Authority (KAA) in terms of ensuring compliance to these standards and regulation to busy airports such as Wilson airport in the recent past. Some literature nevertheless shows Kenyan airports are well equipped in certain areas such fire fighting and that they are some of the facilities in the country with the most effective fire fighting capacity (Halimu, 2007). However, this fire fighting capacity only covers limited areas of airport. This then is an indication of institutional weakness that may limit proper management of disasters when they occur.

\section{Disaster management in Kenya}

Disasters in Kenya have assumed both natural and man-induced characteristics (Onywere, 2005; Mutugi and Maingi, 2011; Akali, Khabamba and Muyinga, 2011). However, a fairly good number of them are weather related meaning that most occur as natural disasters as opposed to man-made disasters (Onywere, 2005). Natural disasters are induced by such hazards as floods, droughts, landslides and lightening, etc. Over the last two decades, a considerable number of human induced disasters have been observed and caused by such hazards such traffic accidents, civil conflicts, terrorism etc. However, in terms of aviation related disasters, they may fall under the two broad typologies of disasters, that is natural and man-made. This is because planning and management failures contribute to aviation disasters in the country. Planning for disaster risk is therefore key to managing disasters in the country, (Omari, Bosire-Ogechi and Otike, 2011).

Disaster management in Kenya has not developed to the extent where systems are fine-tuned to effectively and efficiently prevent, control and manage disasters. Mawanda (2003) puts it that locally, resources are geared towards recovery and reconstruction, rather than prevention or appropriate response. In addition, it would seem that air disasters have been left out in research, particularly in Kenya, as most previous studies have focused on other disasters. For exampleKiema-Ngunnzi (2002) looked at recovery strategies for the 1998 Nairobi bomb blast victims within the Teachers' Service Commission. In order to prevent, control or even mitigate any disaster or any other problem for that matter, the causes of the problem must be brought to the fore.

Lack of disaster preparedness has remained one of Kenya's enduring development challenges for decades. Most of the disaster response initiatives in Kenya tend to be ad hoc, uncoordinated and short term measures, mainly in the form of emergency relief services to the worst affected areas. There is lack of 
recognition of the interrelationship between disaster preparedness, unsustainable production and consumption patterns (GOK, 2009a).

Despite the availability of personnel in Kenyan airports to deal with air crashes/disasters, it would seem that their preparedness in all these airports, including JKIA, is grossly wanting. For example, in a simulation of disaster preparedness at the JKIA airport in June 2002, it took 37 minutes for ambulances and fire engines from without the airport to arrive (Mirichu, 2004). The first reaction that came out was panic, a situation in which proper planning was ruled out (The East African, 2004).

While there have been impressive humanitarian relief efforts in times of crisis, particularly related to natural disasters in Africa, Holloway (2003) says that disaster vulnerability and risk have not been taken as an impotant area of sustainable development planning. In Kenya, more resources have actually been allocated to relief and rehabilitation efforts than prevention. This is a major shortcoming on the part of the government and other stakeholders in the disaster mitigation sector. For example, according to the Kenya Red Cross SocietyKRCS (2009), a fire outbreak in Nakumatt downtown supermarket (Nairobi) in January 2009, saw many relief efforts. In actual fact, the city planners should have foreseen the possibility of such a disaster and advised on house plans.

\section{Disaster policy, institutional and regulatory frameworks in Kenya}

The lessons learned from the major events of the last decade have triggered new laws and regulations that expand prevention strategies and augment response capabilities. The same disaster preparedness and response planning standards that govern cities, counties, states, and federal agencies are now being viewed for their applicability to airports. And as planning moved beyond a focus on surviving a nuclear weapon attack to comprehensive disaster planning, so, too, are airport managers expanding contingency plans from those based primarily on aircraft crashes to all potential emergencies (Stambaugh, 2009).

Increasing regularity of different types of disasters in Kenya prompted the government though the office of the president to formulate a national policy on disaster management (GOK, 2009). The policy was developed to avoid a situation where disasters are mitigated in a reactive and poorly coordinated manner. This government policy document provides general guidelines for development of strategies to address disaster issues. Specific sector guides however ought to be developed separately (GOK, 2009). For instance, in the aviation sector, the onus of developing such policies is entrusted to the Kenya Civil Aviation Authority, (Munyi, 2011; Mokaya and Nyaga, 2009). As of 2009, a safety management system for the sector had not been developed (Mokaya and Nyaga, 2009). This is despite Kenya having had signed the international civil aviation convention while aviation disaster risks continuing being so apparent in our airports and air spaces.

\section{METHODOLOGY}

This study was carried out at Wilson airport located in Nairobi West. The airport is strategically located only about 5 kilometers from Nairobi city centre. The descriptive design was applied in this study to analyze and describe the effects of land use changes on airport and flight safety in a rapidly growing aviation sector. A total of 216 respondents were sampled for the study including 30 aviation regulators, 30 air operators, 6 service providers, and 150 members of the community.

This population has been targeted due to its significant role in either determining issues of preparedness for disaster and risk or being potential causes of disasters and risks at Wilson airport. This study collected primary and secondary data. Primary data was collected by use of questionnaires, interview guide and Focused Group Discussions while Secondary data were collected from written or published records and maps from the Kenya National Bureau of statistics. Qualitative data was analysed by use of descriptive statistics such as frequencies and percentages while qualitative data was analysed using content analysis.

\section{FINDINGS OF THE STUDY}

\subsection{Appropriateness and Adequacy of Existing Physical Infrastructure in Mitigating the Effects Aviation} Risks in the Airport

This section presents findings on the appropriateness of the existing physical infrastructure at Wilson Airport by looking at the capacity of the airport, and the adequacy and efficiency of airport facilities.

\subsubsection{Capacity of Wilson Airport}

Aviation regulators and air operators were asked to indicate whether Wilson Airport has adequate capacity in terms of space and facilities and considering the number of active aircrafts it serves. The study found that $29(62 \%)$ of the respondents indicated that Wilson Airport does not have adequate capacity in terms of space and facilities, while $18(38 \%)$ indicated that Wilson Airport did.According to the National Airports System Plan Report (2010), land use encroachment is a major contributor to prevailing problems around the airport. Of the estimated 18 hectares surveyed as airport land, only 70\% (approx. 13 hectares) is under active 
airport use, and fenced accordingly. This indicates encroachment on airport land, which poses a threat to the security and operations of the airport.

While ICAO provides an international framework for safety areas in the immediate vicinity of runways, there is neither national regulation on land use near airports nor an international agreement on the same (ETSC, 1999). Nonetheless, third-party risk in land use planning and is increasingly gaining attention in relation to aircraft accidents (Caves, 1996). Controlling land use near airports is crucial as this is the area in which most accidents happen. The closer the area is to a runway with the higher the accident risk.

The researcher was able to compare capacity at Wilson Airport in Kenya and Lanseria Airport in South Africa. A summary of findings are presented in Table 1 below.

Table 1 Comparison between Lanseria and Wilson Airports

\begin{tabular}{|l|l|l|l|}
\hline & Item of comparison & Lanseria Airport & Wilson Airport \\
\hline a & Land size & 1260 Hectares & 136 Hectares \\
\hline b & Runway width & 45 Metres & 22 Metres \\
\hline c & Average daily flights & 180 & 160 \\
\hline d & Firefighting personnel & 30 & 10 \\
\hline e & Ambulances & 10 & 1 \\
\hline f & Car Parking lots & 2181 & 150 \\
\hline g & Night flights & 24 hours & 12 hours \\
\hline
\end{tabular}

Source: Author (2014)

The comparison revealed that the two airports handle almost equal landings and take offs per day despite the difference in size; Lanseria Airport is almost ten times the size of Wilson Airport.

A comparison of the width of runways at the two airports revealed that the width of Wilson Airport runway is less than half that at Lanseria Airport in South Africa. The findings reveal there are limited firefighting personnel, parking lots, and ambulances at Wilson Airport compared to Lanseria Airport in South Africa.

The researcher also found that Wilson Airport has flights operating only 12 hours a day while Lanseria Airport operates 24-hours a day, though their capacities in terms of take-offs and landings are more less the same.

\subsubsection{Adequacy of the airport facilities}

On the adequacy of the airport facilities, the study found that $40(70.2 \%)$ of the aviation regulators and air operators indicated that radio navigational aids and instrument approach procedures were very adequate. Additionally, 43 (75\%) respondents indicated that the air field capacity was inadequate; $36(63.2 \%)$ respondents indicated thatthe airport visual aids (such as pavement markings) were inadequate; $33(57.9 \%)$ respondents indicated that the airport lighting was inadequate; $34(40.4 \%)$ respondents indicated that the runway orientation, length, width, and pavement strength were inadequate; and $30(56 \%)$ indicated that the taxiways were inadequate. The findings reveal that even though there are different facilities at Wilson Airport, most of them are inadequate considering the capacity of the airport. According to Antonio (2003), some airports are reaching saturation point which leads to flight delay, particularly when there is bad weather, industrial action, and the like. These results are presented in Table 2 below.

Table 2: Adequacy of the airport facilities

\begin{tabular}{|c|c|c|c|c|c|c|c|c|c|c|c|c|}
\hline \multirow[t]{2}{*}{ Statement } & \multicolumn{2}{|c|}{$\begin{array}{l}\text { Very } \\
\text { adequate }\end{array}$} & \multicolumn{2}{|c|}{ Adequate } & \multicolumn{2}{|c|}{ Neutral } & \multicolumn{2}{|c|}{$\begin{array}{l}\text { Inadequat } \\
\text { e }\end{array}$} & \multicolumn{2}{|c|}{$\begin{array}{l}\text { Not } \\
\text { available } \\
\text { at all }\end{array}$} & \multicolumn{2}{|c|}{ Total (\%) } \\
\hline & $\mathrm{F}$ & $\%$ & $\mathrm{~F}$ & $\%$ & $\mathrm{~F}$ & $\%$ & $\mathrm{~F}$ & $\%$ & $\mathrm{~F}$ & $\%$ & $\mathbf{F}$ & $\%$ \\
\hline Airfield capacity & 2 & 3.5 & 9 & 15.8 & 3 & 5.2 & 43 & 75.0 & 0 & 0 & 57 & 100 \\
\hline $\begin{array}{ll}\begin{array}{l}\text { Airfield } \\
\text { standards }\end{array} & \text { design } \\
\end{array}$ & 3 & 5.2 & 18 & 31.6 & 9 & 15.8 & 27 & 47.4 & 0 & 0 & 57 & 100 \\
\hline $\begin{array}{l}\text { Runway orientation, } \\
\text { length, width, and } \\
\text { pavement strength }\end{array}$ & 0 & 0 & 23 & 40.4 & 0 & 0 & 34 & 59.6 & 0 & 0 & 57 & 100 \\
\hline Taxiways & 7 & 12.3 & 18 & 31.6 & 2 & 3.5 & 30 & 52.6 & 0 & 0 & 57 & 100 \\
\hline Airport visual aids & 10 & 17.5 & 11 & 19.3 & 0 & 0 & 36 & 63.2 & 0 & 0 & 57 & 100 \\
\hline
\end{tabular}


Assessment of the Appropriateness and Adequacy of the Existing Physical Infrastructure in ...

\begin{tabular}{|l|l|l|l|l|l|l|l|l|l|l|l|l|}
\hline Airport lighting & 10 & 17.5 & 14 & 24.6 & 0 & 0 & 33 & 57.9 & 0 & 0 & 57 & 100 \\
\hline $\begin{array}{l}\text { Radio navigational aids } \\
\text { and instrument } \\
\text { approach procedures }\end{array}$ & 0 & 0 & 17 & 29.8 & 0 & 0 & 40 & 70.2 & 0 & 0 & 57 & 100 \\
\hline
\end{tabular}

Source: Author (2014)

In an interview with one of the captains at Wilson, he mentioned that Wilson Airport land has been grabbed thus leaving little space despite the doubling of the capacity in term of planes operating from it. He explained that at the moment, Wilson Airport has over six hundred active aircrafts at its disposal.

"The Kenyan logistical support for the airport is lagging ten years behind. The airport is congested with limited parking space and everywhere is full of bottles, runway lights sometimes fail, and there is only one control tower that was installed since the airport was constructed. All these infringe the safety standard." (Interview: A 63-year old captain from Wilson Airport)

\subsubsection{Efficiency of airport support facilities}

To test on the efficiency of airport support facilities, aviation regulators and air operators were given different statements on the efficiency of airport support facilities. A majority of the respondents - 50 (87.7\%) indicated that aviation fueling facilities are less efficient; $40(70.2 \%)$ indicated airport maintenance is less efficient; $37(64.9 \%)$ indicated drainage is less efficient; and $24(42.1 \%)$ indicated airport fencing is less efficient. According to ECAC/EUROCONTROL (2001), capacity on the ground must match that in the air and vice versa. Only an approach addressing all elements of capacity will result in overall improvement in airport capacity. Aviation associations have criticized the lethargy exhibited by the Kenya Aviation Authority (KAA) in ensuring compliance to these standards and regulation in busy airports such as Wilson Airport. Some literature shows Kenyan airports are well-equipped in fire fighting capacity (Halimu, 2007) but that this capacity covers limited areas of the airport. This reveals institutional weakness and inadequate management when disasters occur. The results are as presented in Table 3 below.

Table 3: Efficiency of airport support facilities

\begin{tabular}{|c|c|c|c|c|c|c|c|c|c|c|c|c|}
\hline \multirow[t]{2}{*}{ Statement } & \multicolumn{2}{|c|}{$\begin{array}{l}\text { Very } \\
\text { efficient }\end{array}$} & \multicolumn{2}{|c|}{ Efficient } & \multicolumn{2}{|c|}{ Neutral } & \multicolumn{2}{|c|}{ Less efficient } & \multicolumn{2}{|c|}{$\begin{array}{l}\text { Not efficient } \\
\text { at all }\end{array}$} & \multicolumn{2}{|c|}{ Total (\%) } \\
\hline & $\mathrm{F}$ & $\%$ & $\mathrm{~F}$ & $\%$ & $\mathrm{~F}$ & $\%$ & $\mathrm{~F}$ & $\%$ & $F$ & $\%$ & $\mathbf{F}$ & $\%$ \\
\hline $\begin{array}{l}\text { Emergency } \\
\text { services }\end{array}$ & 0 & 0 & 10 & 17.5 & 0 & 0 & 30 & 52.6 & 17 & 29.8 & 57 & 100 \\
\hline $\begin{array}{l}\text { Airport } \\
\text { maintenance }\end{array}$ & 2 & 3.5 & 0 & 0 & 0 & 0 & 40 & 70.2 & 15 & 26.3 & 57 & 100 \\
\hline Airport fencing & 0 & 0 & 5 & 8.8 & 0 & 0 & 24 & 42.1 & 28 & 49.1 & 57 & 100 \\
\hline Utilities & 6 & 10.5 & 0 & 0 & 0 & 0 & 32 & 56.1 & 19 & 33.3 & 57 & 100 \\
\hline Drainage & 6 & 10.5 & 4 & 7 & 0 & 0 & 37 & 64.9 & 10 & 17.5 & 57 & 100 \\
\hline $\begin{array}{l}\text { Aviation } \\
\text { fueling } \\
\text { facilities }\end{array}$ & 0 & 0 & 0 & 0 & 0 & 0 & 50 & 87.7 & 7 & 12.3 & 57 & 100 \\
\hline
\end{tabular}

Source: Author (2014)

The study found that $52.6 \%$ of the respondents indicated that emergency services at Wilson airport were not efficient, and this fact is reflected by dilapidated fire engines. During the study, only one fire engine was working. Plate 1 and 2 illustrate the state of fire engines at Wilson airport currently.

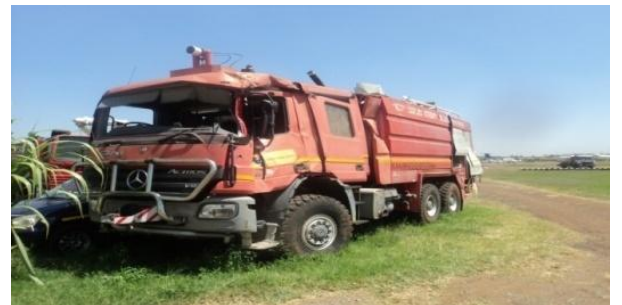

Plate 1: Dilapidated fire Engines at Wilson Airport at the time of the study 
Plate 1 shows run down fire engines parked within Wilson airport, which shows that during emergencies, a quick disaster response would be hampered.

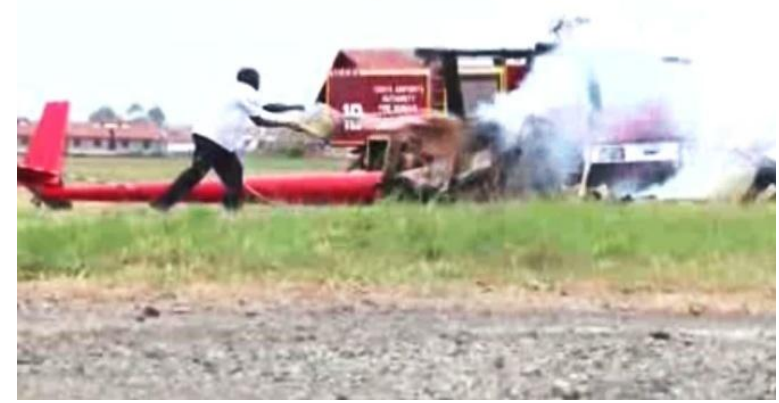

Plate 2: Use of buckets of water to Extinguish fire at Wilson Airport

Plate 2portrays a situation where the fire engines have failed leaving fire fighters with the only option of using hand buckets with water to put off the fire. This is an indication of inefficient of firefighting at Wilson airport.

\subsection{Summary of Findings of the Study}

The study found that $29(62 \%)$ of respondents indicated that Wilson Airport does not have capacity in terms of space and facilities; $43(75 \%)$ of respondents indicated that air field capacity was inadequate; 36 $(63.2 \%)$ of respondents indicated thatairport visual aids (such as pavement markings) were inadequate; 33 $(57.9 \%)$ of respondents indicated that airport lighting was inadequate; $34(40.4 \%)$ of respondents indicated that runway orientation, length, width, and pavement strength, were inadequate; and $30(56 \%)$ indicated that taxiways were inadequate. On the efficiency of the facilities, the study found that most $50(87.7 \%)$ respondents indicated that aviation fueling facilities are less efficient; $40(70.2 \%)$ respondents indicated airport maintenance is less efficient; $37(64.9 \%)$ respondents indicated drainage is less efficient; and $24(42.1 \%)$ respondents indicated airport fencing is less efficient. Thus, security preparedness and adherence to ICAO standards is considered as a major determinant of disaster risk preparedness at Wilson Airport.The results for correlation analysis showed that there is a positive correlation between the disaster preparedness and socio economic and environmental considerations with a Pearson's Correlation Coefficient of $r=0.815$ and a level of significance of 0.000 meaning that is it statistically significant.

\subsection{Conclusion}

It can also be concluded that even though Wilson airport has the required physical infrastructure and facilities, they should be improved in terms of capacity and efficiency to ensure safety and security at the airport.

\subsection{Recommendations}

The study also recommends thatthe aviation regulators (KCAA) needs capacity and employ personnel with knowledge in areas they areas of their work. Airport management should set aside funds to invest in safety equipment such as fire engines and water hydrants.

\section{REFERENCES}

[1] Akali, NM, Khabamba I, Muyinga, GA, (2011).Fire Sources, Disaster Impacts and Mitigation in Kenya Secondary Schools. International Journal of Disaster Mnagement and Risk Reduction, Vol. 3.Issue 3, 2011.

[2] Ayres, M. (2009). Guidebook for Airport Safety Management Systems. Applied Research Associates and International Safety Research inc. [Online]. Retrieved from www.national-academics.org/trb (20/11/2010).

[3] Carrilo, G. (2010). Introduction to disaster management. Course manual. Virtual University for Small States of the Commonwealth (VUSSC). Disaster Management 1.0 [Online]. Retrieved from www.col.org/vussc (4/11/2010).

[4] FEMA. (2006). Disaster management overview. Department of environmental health and safety. Federal Emergency Management Agency. [Online]. Retrieved from www.fema.gov (8/11/2010).

[5] Garatwa, W. \&Bollin, C. (2002). Disaster risk management. A working concept. Deutsche Gesellschaft fur, O.K. KOPIE, Gmbit, Eschborn [Online]. Retrieved from www.gtz.de (26/10/2010).

[6] GOK (2009).Integrated Transport Policy: Moving a Working Nation, Government Press. Nairobi.

[7] Halimu S. Shauri, (2007). Social Services in Disaster Situations in Kenya. Les Cahiers d'Afrique de 1'Est, $n^{\circ} 35$, IFRA, Nairobi, 2007

[8] Holloway, A. (2003). Rising Vulnerability, Increasing Risk. Disaster Risk Reduction. 
[9] ICAO (2004). Annex 14 to the convention on international civil aviation aerodromes-International standards and recommended practices, 4th ed., ICAO Vol.1. Montreal, Canada. [Online]. Retrieved from www.icao.org $(25 / 10 / 2010)$

[10] ICAO (2011). Regional Report, Africa. November-December 2011.

[11] Kapoor, M. (2009). Disaster Management. . New Delhi, India: MotilalBanaisidasi Publishers Private Limited.

[12] KCAA. (2007). Rules of the air and air traffic control regulations. Kenya Civil aviation Authority

[13] Kenya Red Cross. (2009). Nakumatt fire response. [Online]. Retrieved from http://www.krcs.co.ke (10/9/2009).

[14] Kenya Vision 2030 Blueprint (2009)

[15] Kwiatkowski, K U, (2001). Expeditionary Air Operations in Africa: Challenges and Solutions,Fairchild Paper .Alabama: Air University Press.

[16] Mirichu, P. (2004). "Kenya Airports Rescue Plan”. The Journal of Kenya Airports Authority. Vol.11 Issue 4 of April 2004.Nairobi: Kenya Airports Publication

[17] Mokaya, S Chocho, T.A and Kosgey,D, (2009). The Performance of Aviation Regulatory System in Kenya.Paper Presented at the Moi University International Management and Entrepreneurship Conference, August 2009

[18] Momoh,J.A and Akinyede, J.O, (2008),. African Regional Challenges and Position in Space Based Disaster Management and Reduction. African skies, No.12.

[19] Mukaria, S.M (2013). Knowledge, awareness and conformity to International Airport emergency preparedness standards: the case of Wilson Airport in Nairobi, Kenya. Published Thesis. University of Nairobi.

[20] Munyi, I K., (2011).Influence of Organisational Factors on the Adoption of Safety Standards at Wilson Airport Nairobi, MBA Research Project, Moi University.

[21] Murphy, P. (1996) Chaos Theory as a Model for Managing Issues and Crisis. PublicRelations Review 22 (2) 95-113

[22] Mutugi, M.W and Maingi, S.G. (2011). Disasters in Kenya.A major public health Concern.Journal of Public Health and Epidemiology, Vol. 3(1), pp.38-42, January 2011.

[23] Oladele S. F, (2005),. African Air Transport in the 21st Century: A Case Study of the Contrasting Experience of Nigeria and Kenya. MscThesisCranfieldUniversity.

[24] Omari R, Bosire-Ogechi E and Otike, J, (2011).Strategies for Managing Disasters in Libraries and other Information Centres.International Journal of Disaster Mnagement and Risk Reduction, Vol. 3.Issue 3.

[25] Phillips,E.H. (2002).“Aviation Week \& Space Technology”. Vol. 156, no. 16, pp. 44-51.

[26] Salvano, B. (2002). Gender mainstreaming in disaster reduction. International strategy for disaster reduction. [Online]. Retrieved from www.unisdr.org (15/11/2010).

[27] Seeger, M. W. (2002) Chaos and Crisis: Propositions for a General Theory of CrisisCommunication. Public Relations Review 28 (4) 329-337

[28] Stambaugh, H. (2009). An airport guide for regional emergency planning for CBRNE events. Airport cooperative research programme. Report 12, Washington. [Online]. Retrieved from www.national-academics.org/trb $(3 / 11 / 2010)$.

[29] UN/ISDR. (2008). Towards national resilience. Good practices of national platforms for disaster risk reduction, United Nations secretariat of the international strategy for disaster reduction. Geneva, Switzerland. [Online]. Retrieved from www.unisdr.org Available (25/10/2010). 